\title{
Cultivation of Tilapia (Oreochromis niloticus) using the silvofishery method in Tanjungrejo, Percut Sei Tuan, North Sumatra Province
}

\author{
Deni Elfiati $^{1 *}$, Ipanna Enggar Susetya ${ }^{2}$, Delvian $^{1}$, Ridahati Rambey $^{1}$, Amanatul Fadhilah $^{2}$ \\ ${ }^{1}$ Fakultas Kehutanan, Universitas Sumatera Utara \\ ${ }^{2}$ Program Studi Manajemen Sumberdaya Perairan, Fakultas Pertanian \\ Universitas Sumatera Utara \\ *Email: denielfiati@yahoo.com
}

\begin{abstract}
Silvofishery is a mangrove ecosystem management model that combines fisheries and forestry aspects. This method is also a solution for cultivators to cultivate fish without damaging the mangrove ecosystem. It is hoped that the results of this service activity can be used as a model or input for the community in order to manage ponds with silvofishery technology without having to do open ponds which will slowly damage the environment. This community service activity aimed to provide information and skills to partner groups on the silvofishery method. Other aim was to assist partners in the tilapia rearing process. Based on the description of the problems and objectives of this community service activity, the activities that have been carried out are counseling about silvofishery. The second activity, provision of tilapia seeds and feed for fish rearing activities in silvofishery ponds. The results obtained were increased partners' knowledge and skills regarding silvofishery. The people of Tanjungrejo Village also get tilapia cultivation products that can be traded without cutting down mangrove trees.
\end{abstract}

Keyword: cultivation, ponds, silvofishery, tilapia

\begin{abstract}
Abstrak
Silvofishery merupakan salah satu model pengelolaan ekosistem mangrove yang memadukan aspek perikanan dan kehutanan. Metode ini juga sebagai solusi bagi para pelaku budidaya untuk membudidayakan ikan tanpa merusak ekosistem mangrove. Hasil kegiatan pengabdian ini diharapkan dapat dijadikan model atau masukan bagi masyarakat dalam rangka mengelola tambak dengan teknologi silvofishery tanpa harus melakukan tambak terbuka yang perlahan akan merusak lingkungan. Kegiatan pengabdian masyarakat ini bertujuan untuk memberikan informasi dan ketrampilan kepada kelompok mitra tentang metode silvofishery dan membantu mitra dalam proses pembesaran ikan nila. Berdasarkan uraian permasalahan dan tujuan dari kegiatan pengabdian masyarakat ini, maka kegiatan yang telah dilakukan adalah penyuluhan tentang silvofishery. Kegiatan kedua, pemberian benih ikan nila dan pakan untuk kegiatan pembesaran ikan di tambak silvofishery. Hasil yang diperoleh adalah bertambahnya pengetahuan dan ketrampilan mitra tentang silvofishery. Masyarakat Desa Tanjungrejo juga mendapatkan hasil budidaya ikan nila yang bisa diperjualbelikan tanpa melakukan penebangan pohon mangrove.
\end{abstract}

Kata Kunci : budidaya, tambak, mangrove, silvofishery, ikan nila

\section{PENDAHULUAN}

Desa Tanjung Rejo merupakan wilayah pesisir di bagian timur Sumatera Utara, yang memiliki ekosistem mangrove. Menurut Susetya dkk (2019), di desa ini sudah terjadi konversi lahan dari ekosistem mangrove menjadi bentuk lahan lain seperti pertambakan. Ningsih dkk (2011) juga melaporkan bahwa kondisi mangrove di Desa Tanjungrejo berkriteria rusak jika dilihat dari kerapatan pohonnya. Hal ini tentu saja dapat menyebabkan penurunan peran ekosistem mangrove baik secara fisik, ekologi dan ekonomi. 
Keberadaan ekosistem mangrove di Desa Tanjungrejo sangat berpengaruh kepada masyarakat desa yang sebagian besar mata pencaharian masyarakat sangat bergantung pada sektor perikanan. Mangrove merupakan habitat biota seperti ikan, kerang, siput, kepiting dan udang. Mangrove menjadi daerah asuhan dan mencari makan bagi biota-biota tersebut. Kerusakan mangrove tentunya akan menurunkan kelimpahan dari biota yang hidup di dalamnya sehingga menurunkan jumlah tangkapan nelayan. Sejalan dengan pendapat Agungguratno dan Darwanto (2016) yang menyatakan bahwa kerusakan ekosistem mengrove menyebabkan menurunnya produktivitas ikan menurun. Ketersediaan pakan alami yang berasal dari serasah mangrove juga bisa mengalami penurunan.

Selanjutnya Agungguratno dan Darwanto (2016) menyatakan penyebab utama kerusakan mangrove adalah konversi hutan mangrove menjadi lahan tambak dan hilangnya beberapa sumberdaya pesisir. Pola pikir masyarakat tentang keuntungan hasil budidaya yang lebih besar dengan mengubah lahan mengrove menjadi tambak menjadi salah satu penyebab banyaknya kegiatan konversi ini. Ancaman besar seperti abrasi tentunya dapat memberikan kerugian besar di masa yang akan datang jika konversi lahan terus dilakukan

Melihat pentingnya keberadaan mangrove di wilayah pesisir, maka dalam pengabdian ini menawarkan solusi dengan melakukan budidaya silvofishery. Tambak silvofishery merupakan tambak ramah lingkungan karena memadukan tambak dan vegetasi mangrove dalam suatu bentang lahan sehingga tercipta pengelolaan lahan berkelanjutan dari segi ekonomi dan ekologi. Hal ini sesuai dengan Agungguratno dan Darwanto (2016) yang enyatakan bahwa tambak wanamina atau silvofishery dapat menjadi solusi alternatif untuk pengelolaan pesisir dan menjadi model konservasi mangrove yang akomodatif.

Kegagalan panen tambak ikan sering terjadi akibat kurangnya teknologi yang tepat sehingga mengakibatkan kerugian petambak itu sendiri. Pemilihan jenis ikan serta ekologi tambak menjadi faktor penting dalam keberhasilan mengelola tambak. Ikan yang dipilih dalam budidaya silvofishery ini adalah ikan nila, karena kemampuan adaptasi yang tinggi. Ikan ini juga bisa dibudidayakan pada perairan payau. Pertumbuha yang cepat juga menjadi alasan pemilihan ikan ini untuk kegiatan budidaya silvofishery. Djunaedi dkk (2016) juga menyatakan bahwa sifat biologis ikan nila memeiliki kelebihan sperti mamapu mencerna makanan secara efisien, memiliki pertumbuhan cepar, lebih resisten terhadap penyakit, dan memiliki toleransi yang tinggi terhadap berbagai kondisi lingkungan.

Mitra kegiatan pengabdian masayarakan mono tahun regular tahun 2020 saat ini adalah kelompok mandiri yang terdiri dari bapak-bapak penggiat budidaya tambak dan rehabilitasi lahan mangrove di Desa Tanjung Rejo, Kecamatan Percut Sei Tuan. Mitra pengabdian sebagian besar bekerja di lahan budidaya tambak, pertanian dan perkebunan di desa tersebut. Untuk meningkatkan pengetahuan, ketrampilan, perekonomian mitra melalui kegiatan budidaya ikan nila (pembesaran), serta menjaga kelestarian mangrove di Desa Tanjungrejo, maka kegiatan pengabdian ini perlu untuk dilaksanakan.

\section{METODE PELAKSANAAN}

Metode pelaksanaan yang digunakan untuk mengatasi permasalahan mitra adalah dengan melakukan penyuluhan tentang silvofishery. Penyuluhan dilaksanakan pada tanggal 12 September 2020 sekaligus melakukan pembenahan tambak silvofishery. Kegiatan yang dilakukan setelah penyuluhan adalah pemberian benih ikan nila dan pakan kepada mitra pengabdian supaya kegiatan budidaya dapat segera dilaksakan. Pemberian benih ikan nila dan pakan berupa pellet dilakukan pada tanggal 15 September 2020. Pengukuran panjang dan berat ikan nila juga dilakukan pada awal dan menjelang akhir kegiatan untuk melihat pertumbuhan ikan nila 


\section{HASIL DAN PEMBAHASAN}

\subsection{Penyuluhan}

Kegiatan penyuluhan dilakukan langsung di sekitar tambak silvofishery dan dihadiri oleh perwakilan mitra pengabdian. Hal ini dilakukan mengingat kegiatan ini dilaksanakan pada masa pandemi COVID-19 sehingga tidak mengundang banyak orang. Tujuan kegiatan ini adalah untuk menyampaikan informasi tentang silvofishery, cara pelaksanaan budidaya dan membicarakan teknis pembenahan tambak. Indikator keberhasilan kegiatan penyuluhan ini adalah kemampuan mitra dalam pembenahan tambak dan keberhasilan mitra dalam melakukan pembesaran ikan nila sampai masa 4 bulan pemeliharaan.

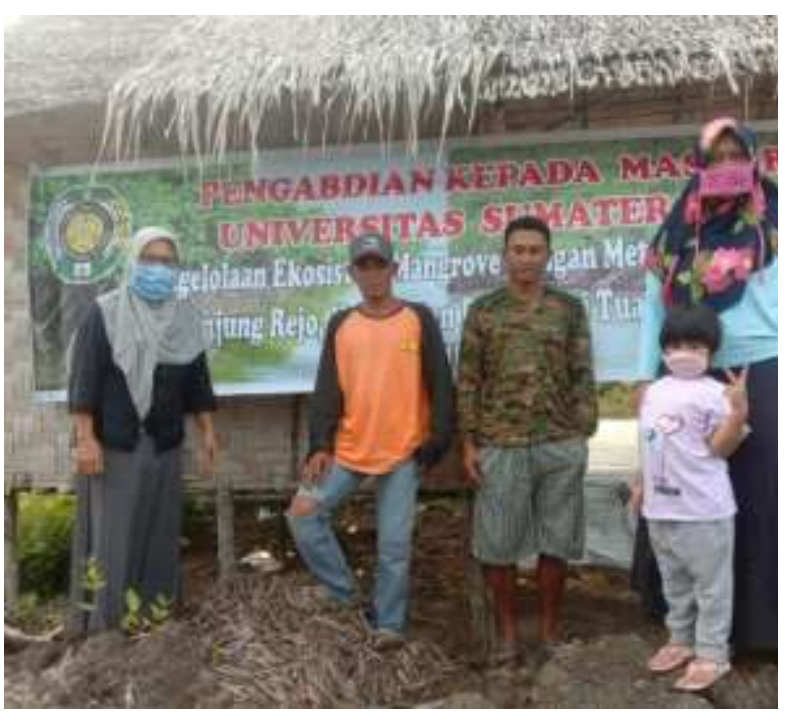

a

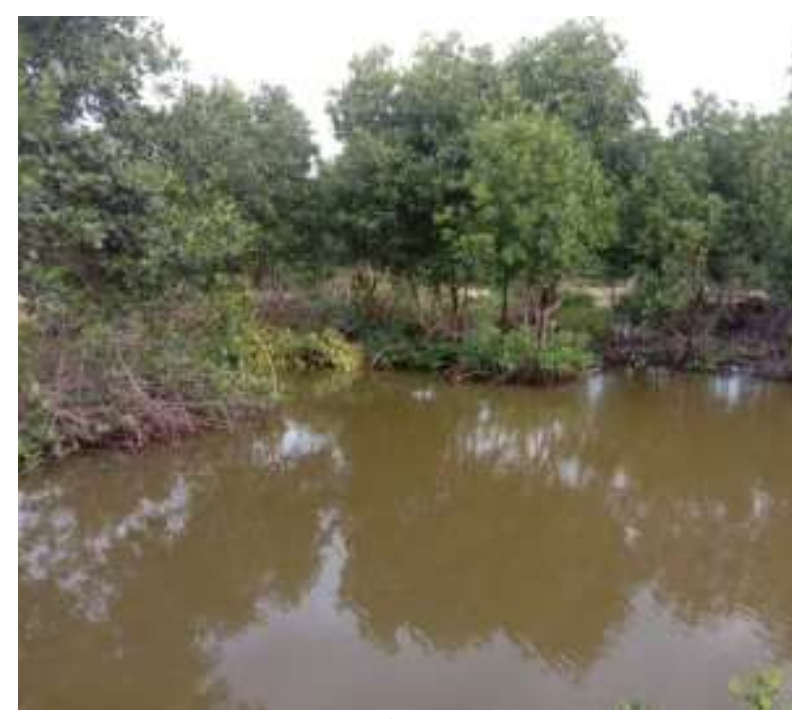

b

Gambar 3.1. (a) Kegiatan Penyuluhan, (b) tambak silvofishery

Pola tambak yang dibuat oleh petani adalah pola tambak empang parit. Desain pola ini sederhana dan ramah lingkungan karena hanya membuat parit di sekitar lahan mangrove dengan 1 pintu air. Pola ini telah banyak berkembang di wilayah pesisir di Indonesia. Ikan ditabur pada empang parit tanpa merusak habitat mangrove. Terjadi interaksi saling menguntungkan dengan adanya pola empang parit ini antara ikan dan habitatnya. Menurut Gunawan dkk. (2007), empang parit merupakan bentuk silvofishery secara tradisional yang telah dipraktekkan dalam pengelolaan mangrove dan tambak terpadu.

\subsection{Pemberian Benih Ikan Nila dan Pakan Pellet}

Pemberian benih ikan nila dilakukan pada tanggal 15 September 2020 sebanyak 20.000 ekor. Benih ikan nila disebarkan pada tambak yang diberi sekat jaring dengan ukuran yang disesuaikan. Benih ikan nila tidak langsung dilepasliarkan agar ikan nila dapat beradaptasi terlebih dahulu. Ukuran berat benih ikan nila yaitu rata-rata 2,5 sd 3,5 gram dengan panjang 3,5 sd 4,5 cm (Gambar 3.2). 


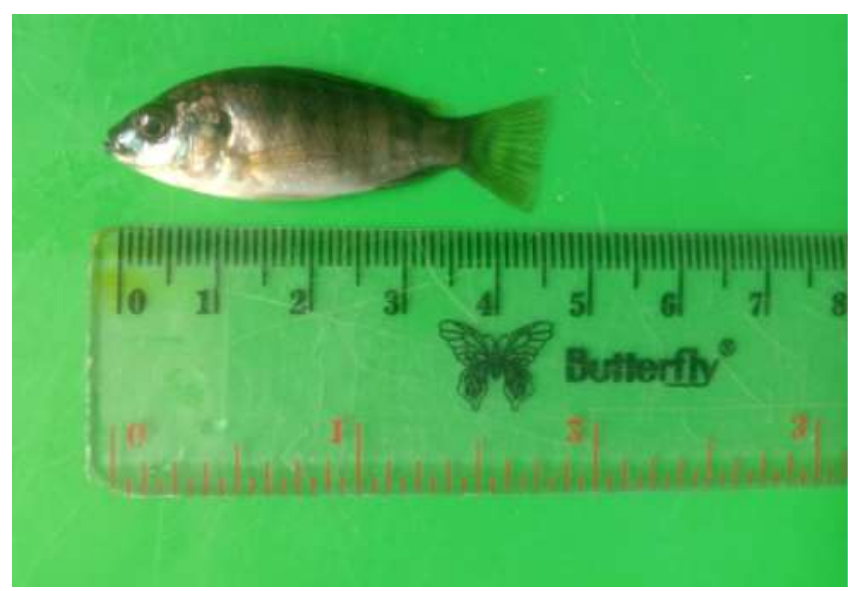

Gambar 3.2. Benih ikan nila .

Ikan nila yang baru dimasukkan ke dalam tambak selama 3 sampai dengan umur 4 minggu diberi pakan pellet (pakan buatan pabrik). Pemberian pakan dilakukan dua kali sehari yaitu pada pagi hari dan sore hari (Gambar 3.3). Hal ini sesuai dengan Djunaedi dkk. (2016) dan Priyanto dkk. (2016) yang melakukan pemberian pakan benih ikan nila dua kali sehari (pagi dan sore) sebesar $5 \%$ dari bobot ikan. Setelah ikan nila berumur 3 sampai dengan 4 minggu jaring dibuka dan ikan nila dilepas liarkan pada tambak untuk mencari pakan alami sendiri.

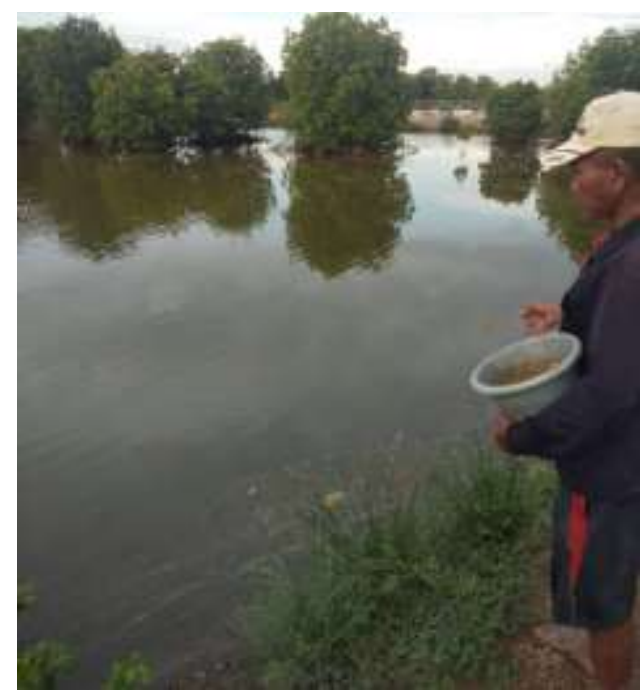

Gambar 3.3. Pemberian pakan pellet benih ikan nila.

\subsection{Monitoring}

Kegiatan monitoring dilakukan untuk melihat pertumbuhan ikan nila selama periode budidaya bulan September sampai awal Desember 2020. Berdasarkan hasil pengamatan, ikan nila telah mencapi berat rata-rata 150 gram dengan panjang $18 \mathrm{~cm}$ pada awal bulan Desember. Hal ini diasumsikan bahwa ikan nila berhasil mencari pakan alami sendiri pada ekosistem mangrove. Ikan akan dipanen ketika umur 4 bulan (bulan Januari) dan saat ini masih tahap pemeliharaan. 


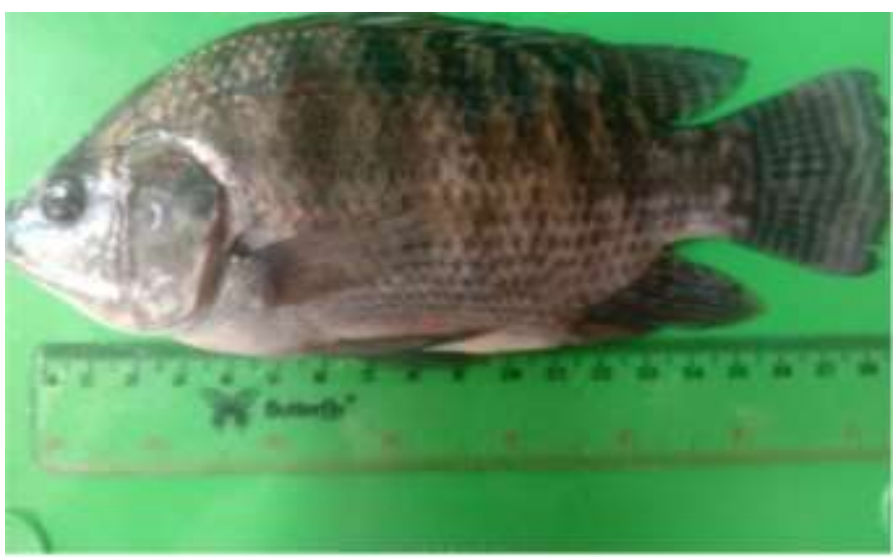

Gambar 3.4. Panjang ikan nila berumur 2,5 bulan

Budidaya ikan nila dengan model silvofishery ini menguntungkan bagi petani dimana mempunyai kelebihan biaya produksi yang rendah dan ekologi mangrove setempat tetap terjaga. Jenis pohon yang berada di tambak dibiarkan tumbuh alami. Jenis pohon anatara lain Avicennia marina, Rhizopora apiculata, Rhizopora stylosa, Lumnitzera sp dan lain-lain. Serasah tumbuhan mangrove yang jatuh di sekitar tambak akan terdekomposisi oleh mikro dan makrofauna dan menjadi sumber pakan bagi ikan, kepiting dan lain-lain, sehingga terjadi satu pola rantai makanan pada tambak silvofishery

\section{KESIMPULAN}

Rangkaian kegiatan pengabdian masyarakat di Desa Tanjungrejo, Kecamatan Percut Sei Tuan telah selesai dikakukan. Mitra pengabdian telah mengetahui dan mampu mempraktekkan budidaya ikan nila dengan metode silvofishery. Pembesaran ikan nila juga telah berhasil dilakukan dengan indicator pertumbuhan berat mencapai $150 \mathrm{gr}$ dan panjang mencapai $18 \mathrm{~cm}$ selama 2,5 bulan waktu pemeliharaan.

\section{UCAPAN TERIMAKASIH}

Ucapan terima kasih penulis ucapkan kepada Universitas Sumatera Utara yang memberikan dana kegiatan pengabdian kepada masyarakat melalui dana NON PNBP Universitas Sumatera Utara. Sesuai dengan Surat Perjanjian Penugasan Pelaksanaan Pengabdian kepada Masyarakat Program Dosen Mengabdi Tahun Anggaran 2020 Nomor : 666/UN5.2.3.2.1/PPM/2020, Tanggal 24 Juli 2020 (untuk Batch I) Nomor : 754/UN5.2.3.2.1/PPM/2020, Tanggal 25 September 2020 (untuk Batch II). Selanjutnya, ucapan terima kasih penulis ucapkan kepada ketua, sekertaris dan segenap pegawai LPPM USU yang telah membantu penulis dalam pelaksanaan kegiatan. Kepada mitra pengabdian penulis juga mengucapkan terima kasih atas kerja samanya selama kegiatan berlangsung. 
Deni Elfiati et.al. Cultivation of Tilapia (Oreochromis niloticus) using the silvofishery method

\section{DAFTAR PUSTAKA}

Agungguratno, E.Y. dan Darwanto. (2016). Penguatan ekosistem mangrove untuk pemberdayaan ekonomi masyarakat pesisir. Eko-Regional, 11, 1-9.

Djunaedi, A., Hartati, R., Pribadi, R., Redjeki, S., Astuti, R.W., Septiarani, B. (2016). Pertumbuhan ikan Nila Larasati (Oreochromis niloticus) di Tambak dengan Pemberian Ransum Pakan dan Padat Penebaran yang Berbeda. Jurnal Kelautan Tropis, 19, 131-142

Gunawan, H., Anwar, C., Sawitri, R., Karlina, E. (2007). Status Ekologis Silvofishery Pola Empang Parit di Bagian Pemangkuan Hutan Ciasem-Pamanukan, Kesatuan Pemangkuan Hutan Purwakarta. Jurnal Penelitian Hutan dan Konservasi Alam, IV, 429-439.

Ningsih, S.S., Widhiastuti, R., Utomo, B., Guslim. (2011). Inventarisasi hutan mangrove sebagai bagian dari upaya pengelolaan wilayah pesisir Deli Serdang, Sumatera. Bonorowo Wetlands, 1, 58-69.

Priyanto, Y., Mulyana, dan Mumpuni, F.S. (2016). Pengaruh Pemberian Daun Ketapang (Terminalia Catappa) Terhadap Pertumbuhan dan Tingkat Kelangsungan Hidup Benih Ikan Nila (Oreochromis Niloticus). Jurnal Pertanian, 7, 44-50.

Susetya, I.E., Dewinta, A.F., Rambey, R., Sudiati, Azhari, Suriani, M. (2019). Community empowerment through making maroca (mangrove root craft) in village Tanjung Rejo, Kecamatan Percut Sei Tuan, Sumatera Utara. Abdimas Talenta, 4, 200-205. 